\title{
FAKTOR YANG MEMPENGARUHI SISA MAKANAN DAN BIAYA YANG TERBUANG PADA PASIEN SKIZOFRENIA RAWAT INAP
}

\author{
Astri Fitriati $^{1 *}$, Reni Sofiyatin ${ }^{1}$, Suhaema $^{1}$ dan Luh Suranadi ${ }^{1}$ \\ ${ }^{1}$ Jurusan Gizi, Poltekkes Kemenkes Mataram, Indonesia \\ Jl. Praburangkasari Dasan Cermen, Sandubaya Kota Mataram \\ Telp./Fax. (0370) 633837 \\ *Email : astrifitriati79@gmail.com
}

\begin{tabular}{l} 
Article Info \\
\hline Article history: \\
Received July $15^{\text {th }}, 2021$ \\
Revised August $20^{\text {th }}, 2021$ \\
Accepte September $25^{\text {th }}, 2021$ \\
\hline
\end{tabular}

Keyword:

Costs; Food Waste;

Schizophrenic Patients

\section{Kata Kunci :}

Biaya Sisa Makanan; Pasien Skizofrenia; Sisa Makanan

\begin{abstract}
Background : The success of a food maintenance system can be evaluated by observation of food waste that causes the cost to be wasted and will have an impact on the anggran used for the procurement of foodstuffs. The observations showed that in Mutiara Sukma Mental Hospital, there were still food waste that was not consumed by patients.
\end{abstract}

Objective : This study aims to analyze "factors that affect food waste and its relationship to the cost of food waste".

Method : The type of research is cross sectional with survey approach. Respondents to this study were 24 patients who underwent hospitalization from December 1 to 10, 2020. The food waste data was taken by observation using Comstock's visual method and compared with the price of the menu, patient assessment data on food taste was obtained by interview using questionnaires. The relationship between food waste and food waste costs was obtained by pearson correlation tests.

Result : Average food waste in period 1 menu cycle of 9.07\%, from the results of double logistic regeresi test there is no relation between food waste wit ofh age, gender and taste of food. The cost of food waste cost per patient per day is Rp. 2283.5,-

Conclusion : Food waste correlated with the cost of food waste.

\begin{tabular}{l} 
ABSTRAK \\
Latar belakang : Keberhasilan suatu sitem penyelenggaraan \\
makanan dapat dievaluasi dengan pengamatan sisa makanan yang \\
menyebabkan adanya biaya yang terbuang secara sia-sia dan akan \\
berdampak terhadap anggaran yang digunakan untuk pengadaan \\
bahan makanan. Hasil observasi menunjukkan bahwa di Rumah \\
Sakit Jiwa Mutiara Sukma masih ditemukan adanya sisa makanan \\
yang tidk dikonsumsi oleh pasien. \\
Tujuan : Penelitian ini bertujuan untuk menganalisis "Faktor- \\
faktor yang mempengaruhi sisa makanan dan hubungannnya dengan \\
biaya sisa makanan”. \\
Metode : Jenis penelitian adalah cross sectional. Responden \\
sebanyak 24 pasien yang menjalani rawat inap di ruang pemulihan. \\
Waktu penelitian 1-10 Desember 2020. Metode visual Comstock \\
untuk pengukuran sisa makanan kemudian melihat biaya dari sisa \\
dengan membandingkan dengan harga menu persajian. Analisis \\
faktor yang mempengaruhi sisa dengan uji regresi logistk ganda dan \\
melihat hubungan antara sisa makanan dan biaya sisa makanan \\
\hline
\end{tabular}




\section{diperoleh dengan uji korelasi pearson.}

Hasil : Rata-rata sisa makanan dalam periode 1 siklus menu sebesar $9.07 \%$, tidak terdapat hubungan antara sisa makanan dengan umur, jenis kelamin dan cita rasa makanan. Biaya sisa makanan per pasien perhari sebesar Rp. 2283.5.

Kesimpulan : Sisa makanan berkorelasi dengan biaya sisa makanan.

\section{PENDAHULUAN}

Sisa makanan merupakan salah satu indikator dalam mengevaluasi keberhasilan suatu penyelenggaraan makanan di Rumah Sakit . Sisa yang banyak menunjukkan pemberian makanan yang kurang optimal (Djamaluddin et al., 2005). Menurut Wirasamadi et al., 2015 banyaknya sisa makanan secara ekonomi menunjukkan banyaknya biaya yang terbuang dan berdampak juga pada pemenuhan kebutuhan zat gizi pasien tidak adekuat. Hasil penelitian (Nida et al., 2011) pada pasien rawat inap di RSJ Sambang Lihun menunjukan sisa makanan yang paling banyak pada jenis sayur sebanyak 67,8 \%, lauk hewani bersisa 52,2\% dan lauk nabati bersisa 50,8\%. Hal ini sejalan dengan hasil penelitian yang dilakukan oleh Irawati (2010) di Rumah Sakit Jiwa Madani Palu menunjukkan hasil sisa makanan sayur sebesar 26,8\%, lauk hewani sebesar $7,75 \%$ dan lauk nabati bersisa $14,85 \%$. Beradasarkan observasi secara visual yang dilakukan di Instalasi gizi pada Bulan Agustus, September dan Oktober menunjukkan masih adanya sisa makanan terutama untuk jenis hidangan sayur di ruang rawat inap pemulihan kelas III. Berdasarkan uraian permasalahan diatas, peneliti ingin melakukan penelitian tentang "Analisis Faktor-faktor Yang Mempengaruhi Sisa Makanan dan Hubungannya Dengan Biaya Sisa Makanan Pasien Skizofrenia Rawat Inap di Rumah Sakit Jiwa Mutiara Sukma Provinsi NTB".

\section{METODE PENELITIAN}

Desain penelitian cross sectional,dengan jumlah sampel jenuh sebanyak 24 orang pasien kelas III diruang pemulihan Rumah Sakit Jiwa Mutiara Sukma Provinsi NTB. Waktu penelitian dilakukan pada tanggal 1- 10 Desember 2020. Data yang dinalasisi dengan uji statistic regresi logistik ganda (Logistic Regression Multivariat). Analisis hubungan antara sisa makanan dengan biaya sisa makanan menggunakan uji korelasi pearson.

\section{HASIL DAN PEMBAHASAN PENELITIAN}

Karakteristik Subyek

Subyek pada penelitian ini adalah. Jumlah subyek pada penelitian ini sebanyak 24 orang.

Tabel 1. Distribusi Subyek Berdasarkan Karakeristik Pasien

\begin{tabular}{ccc}
\hline Varibael & $\mathbf{n}$ & $\mathbf{\%}$ \\
\hline Umur & & 41,7 \\
$19-29$ tahun & 10 & 50 \\
$30-49$ tahun & 12 & 8,3 \\
$50-65$ tahun & 2 & 100 \\
\hline Total & 24 & 70,8 \\
\hline Jenis kelamin & 17 & 29,2 \\
Laki-laki & 7 & 100 \\
Perempuan & 24 & 75 \\
\hline Total & 18 & 25 \\
\hline Jenis Penyakit & 6 & 100 \\
Skizofrenia paranoid & 24 & 45,8 \\
Skizifrenia tak terinci & & 54,2 \\
\hline Total & 11 & 100 \\
\hline Lama rawat & 13 &
\end{tabular}


Tabel 1 menunjukkan dari 24 orang sampel, sebanyak $50 \%$ berada di usia 30-49 tahun, berjenis kelamin laki-laki sebesar 70,8\%, 75\% menderita skizofrenia paranoid. Sedangkan berdasarkan lama rawat diperoleh data $54,2 \%$ lama rawat $>16$ hari.

\section{Standar Porsi Makanan Biasa Pasien Rumah Sakit Jiwa Mutiara Sukma Provinsi NTB}

Tabel 2. Standar Porsi Makanan Biasa RSJ Mutiara Sukma Provinsi NTB

\begin{tabular}{lccc}
\hline \multicolumn{1}{c}{ Bahan Makanan } & Satuan & Standar Porsi & Energi (kkal) \\
\hline Beras & Gram & $100 / 125 / 125$ & 1.225 \\
Daging sapi/ayam/telur & Gram & $60 / 60 / 60$ & 345,6 \\
Tempe/tahu & Gram & $50 / 50$ & 120 \\
Sayuran & Gram & $75 / 100 / 100$ & 137,5 \\
Buah & Gram & $100 / 100$ & 80 \\
Gula & Gram & 20 & 78,8 \\
Snack & Buah & 1 & 148 \\
Minyak & Gram & 30 & 270 \\
\hline & Total & & 2404,9 \\
\hline
\end{tabular}

Instalasi gizi RSJ Mutiara Sukma menetapkan standar porsi untuk beras adalah 100 gram untuk makan pagi dan 125 gram untuk makan siang dan sore, untuk lauk hewani sebesar 60 gram, sedangkan untuk lauk nabati sebesar 50 gram dan buah sebesar 100 gram di berikan pada saat makan siang dan sore. Standar energy makanan sehari untuk pasien di RSJ Mutiara Sukma adalah 2404,9 kkal.

\section{Biaya Makanan Biasa Pasien Kelas III RSJ Mutiara Sukma}

Dari hasil penelitian diketahui bahwa total biaya makan sehari untuk pasien rawat inap kelas III yang mendapatkan makanan biasa adalah sebesar Rp. 47.000,-. Harga tersebut sudah termasuk dengan pemberian 1 kali snack dan teh. Perhitungan biaya makanan pasien di RSJ Mutiara Sukma hanya berdasarkan biaya yang dikeluarkan untuk pembelian bahan makanan tanpa memperhitungkan biaya tenaga kerja dan biaya overhead lainnya. Hal ini karena biaya makan pasien belum menggunakan unit cost tetapi masuk ke dalam akomodasi rawat inap rumah sakit.

Persentase Sisa Makanan Subyek di RSJ Mutiara Sukma Provinsi NTB

Tabel 3. Sisa Makanan Berdasarkan Siklus Menu

\begin{tabular}{|c|c|c|c|c|c|c|}
\hline \multirow[b]{2}{*}{$\begin{array}{c}\text { Menu } \\
\text { Ke }\end{array}$} & \multicolumn{5}{|c|}{ Sisa Makanan } & \multirow{2}{*}{$\begin{array}{c}\text { Sisa } \\
\text { Makanan } \\
\text { Perhari } \\
(\%)\end{array}$} \\
\hline & Nasi (\%) & $\begin{array}{c}\text { Lauk Hewani } \\
(\%)\end{array}$ & $\begin{array}{c}\text { Lauk Nabati } \\
(\%)\end{array}$ & Sayur (\%) & Buah $(\%)$ & \\
\hline $\mathrm{I}$ & 12,1 & 9,7 & 12,8 & 18,7 & 0,3 & 10,4 \\
\hline II & 16,9 & 11,8 & 13,6 & 22,2 & 0,1 & 13,7 \\
\hline III & 13,8 & 5,9 & 12,1 & 19,4 & 0,0 & 9,6 \\
\hline IV & 11,8 & 2,4 & 3,5 & 19,8 & 0,0 & 8,4 \\
\hline V & 8,7 & 2,7 & 4,8 & 14,9 & 0,0 & 6,2 \\
\hline VI & 8,6 & 1,1 & 1,4 & 10,8 & 0,0 & 4,9 \\
\hline VII & 13,5 & 6,6 & 8,8 & 16,7 & 1,4 & 9,7 \\
\hline VIII & 13,4 & 5,5 & 9,0 & 10,8 & 0,0 & 8,3 \\
\hline IX & 18,1 & 5,9 & 8,1 & 19,1 & 0,0 & 9,7 \\
\hline$X$ & 14,2 & 6,3 & 7,6 & 22,9 & 0,3 & 9,8 \\
\hline $\begin{array}{l}\text { Rata- } \\
\text { rata }\end{array}$ & 13,1 & 5,8 & 8,2 & 17,5 & 0,2 & 9,07 \\
\hline
\end{tabular}

Berdasarkan tabel 3. Persentase sisa makanan tertinggi terdapat pada siklus menu ke-2 dengan persentase sisa makanan sebesar $13,7 \%$, tingginya sisa makanan pada siklus menu ke-2 diakibatkan oleh tingginya sisa makanan pada jenis sayuran yaitu sebesar 22,2\%. Nasi meninggalkan sisa makanan sebesar 16,9\%. Lauk 
nabati meninggalkan sisa sebesar $13,6 \%$, sedangkan lauk hewani meninggalkan sisa sebesar $11,8 \%$ dan sisa makanan dari buah sebesar $0,1 \%$.

Faktor Yang Mempengaruhi Terjadinya Sisa Makanan

Sisa makanan dipengaruhi oleh beberapa faktor yaitu jenis kelamin, kelompok umur, cita rasa makanan, tingkat pendidikan, kelas perawatan dan penyakit ( Almatsier ,2009). Tabel 4 menunjukkan hasil analisis regresi logistic ganda menunjukkan variable umur,jenis kelamin dan rasa makanan mempunyai nilai $\mathrm{p}<0,25$ dan akan dilakukan uji multivarian

Tabel 4. Hubungan Umur, Jenis Kelamin, Aroma, Rasa, Warna Dan Variasi Makanan Dengan Sisa Makanan

\begin{tabular}{|c|c|c|c|c|c|}
\hline \multirow{3}{*}{ Variabel } & \multicolumn{4}{|c|}{ Sisa Makanan } & \multirow{3}{*}{ P value } \\
\hline & \multicolumn{2}{|c|}{ Banyak } & \multicolumn{2}{|c|}{ Sedikit } & \\
\hline & $\mathbf{n}$ & $\%$ & $\mathbf{n}$ & $\%$ & \\
\hline Umur & & & & & \\
\hline 18-29 tahun & 0 & 0 & 10 & 100 & 0,138 \\
\hline 30-49 tahun & 4 & 33,3 & 8 & 66,7 & \\
\hline 50-64 tahun & 1 & 50 & 1 & 50 & \\
\hline Jenis Kelamin & & & & & \\
\hline Laki-laki & 1 & 5,9 & 16 & 94,1 & 0,017 \\
\hline Perempuan & 4 & 57,1 & 3 & 42,8 & \\
\hline Aroma & & & & & \\
\hline Sangat memuaskan & 0 & 0 & 1 & 100 & 0,893 \\
\hline Memuaskan & 5 & 21,7 & 18 & 78,3 & \\
\hline Rasa & & & & & \\
\hline Sangat memuaskan & 1 & 100 & 0 & 0 & 0,249 \\
\hline Memuaskan & 4 & 17,4 & 19 & 82,6 & \\
\hline Warna & & & & & \\
\hline Sangat memuaskan & 1 & 50 & 1 & 50 & 0,935 \\
\hline Memuaskan & 4 & 18,2 & 18 & 81,8 & \\
\hline Variasi & & & & & \\
\hline Sangat memuaskan & 0 & 0 & 1 & 100 & 0,542 \\
\hline Memuaskan & 5 & 21,7 & 18 & 78,3 & \\
\hline
\end{tabular}

Tabel 5. Faktor yang mempengaruhi terjadinya sisa makanan

\begin{tabular}{lcccccc}
\hline & B & S.E & Wald & Df & Sig. & Exp (B) \\
\hline Umur & 1.306 & 1.394 & 0.878 & 1 & 0.349 & 3.691 \\
Jenis Kelamin & 2.444 & 1.362 & 3.218 & 1 & 0.073 & 11.515 \\
Rasa & 20.781 & 4.019 & 0.000 & 1 & 1.000 & 105.974 \\
Constant & -3.328 & 1.306 & 6.494 & 1 & 0.011 & 0.036 \\
\hline
\end{tabular}

Berdasarkan Tabel 5. Menunjukkan umur mempunyai nilai $\mathrm{p}=0,349(\mathrm{p}>0,05)$, jenis kelamin mempunyai nilai $\mathrm{p}=0,073(\mathrm{p}>0,05)$ pada rasa makanan mempunyai nilai $\mathrm{p}=1,000(\mathrm{p}>0,05)$ yang berarti bahwa sisa makanan tidak dipengaruhi oleh umur,jenis kelamin dan rasa makanan. Banyak faktor yang mempengaruhi sisa makanan. Pada penelitian ini menunjukkan bahwa bahwa faktor umur,jenis kelamin tidak mempengaruhi sisa makanan. Hal ini sejalan dengan penelitian yang dilakukan oleh Irawati (2010) di RSJ Madani Palu yang menunjukan tidak ada perbedaan sisa makanan menurut kelompok umur dan jenis kelamin. Sedangkan penelitian yang dilakukan oleh Djamaluddin (2005) di RS. Dr. Sardjito Yogyakarta yang menyatakan bahwa ada perbedaan antara sisa makanan menurut jenis kelamin.

\section{Hubungan Sisa Dan Biaya Yang Terbuang}

Hasil analisis menunjukkan terdapat hubungan yang signifikan antara sisa makanan dengan biaya yang terbuang $(\mathrm{p}=0,000)$. Persentase biaya sisa makanan pada pasien di ruang pemulihan tertinggi pada siklus menu ke-2 dengan persentase biaya sisa makanan sebesar $12,9 \%$ dari total harga makanan pada hari tersebut dengan harga sisa makanan pada siklus menu ke-2 adalah sebesar 3069,8. Tingginya biaya sisa makanan 
pada siklus menu ke-2 diakibatkan oleh tingginya sisa makanan pada jenis lauk hewani dengan persentase sisa makanan dari jenis lauk hewani sebesar 11,8\%. Biaya sisa makanan yang tinggi pada hari tersebut diakibatkan penggunaan fillet ikan kakap yang pada dasarnya memiliki harga satuan bahan makanan tersebut lebih tinggi dibandingkan dengan lauk hewani lainnya sehingga menjadikan biaya sisa makanan lauk hewani tersebut menjadi tinggi. Sedangkan biaya sisa makanan yang terendah terdapat pada siklus menu ke- 6 dengan persentase yang hilang dari sisa makanan adalah sebesar 3,8\% dengan nilai rupiah sebesar Rp. 1095.5,Adapun persentase rata-rata biaya sisa makanan pasien dalam satu siklus menu adalah sebesar 8,5\% dari standar harga makanan pasien kelas III RSJ Mutiara Sukma. Menurut (Mas'ud et al., 2015) Idealnya makanan yang disajikan habis dimakan oleh pasien dan biaya yang terpakai sesuai dengan alokasi dana . Biaya sisa makanan adalah nilai ekonomis yang terdapat pada sisa makanan yang tidak dapat digunakan kembali untuk dikonsumsi dan dibuang (Tanuwijaya et al., 2010)

\section{KESIMPULAN}

Tidak terdapat hubungan yang signifikan antara umur, jenis kelamin, aroma, rasa, warna dan variasi makanan dengan terjadinya sisa makanan pasien di RSJ Mutiara Sukma. Sisa makanan tertinggi terdapat pada siklus menu ke-2 dengan 22,2\% sisa makanan berasal dari jenis olahan sayur. Rata-rata sisa makanan pasien sebesar 9,07\% dengan baiaya sisa makanan tertinggi pada siklus menu ke-2 diakibatkan oleh tingginya sisa makanan pada jenis lauk hewani dengan persentase sebesar $11,8 \%$. Sedangkan rata-rata biaya sisa makanan perhari sebesar Rp. 2283.5,- Terdapat hubungan signifikan antara sisa makanan pada pasien dengan biaya sisa makanan.

\section{SARAN}

Mengevaluasi kembali siklus menu 10 hari dan untuk menu dengan sisa makanan tinggi terutama jenis hidangan sayur dan lauk hewani agar lebih bervariasi baik jenis maupun cara pengolahan.

Perlu dilakukan penelitian penelitian lanjutan untuk mengukur sisa makanan di ruang intesnsif sehingga dapat menggambarkan sisa makanan dan biaya yang yang terbuang secara keseluruhan.

\section{DAFTAR PUSTAKA}

Almatsier, S. (2009). Ilmu gizi dasar. PT Gramedia Pustaka Utama, Jakarta.

Djamaluddin, M., Prawirohartono, E. P., \& Paramastri, I. (2005). Analisis zat gizi dan biaya sisa makanan pada pasien dengan makanan biasa. Jurnal Gizi Klinik Indonesia. https://doi.org/10.22146/ijcn.17379

Fadilah, O. dkk. (2013). Gambaran Sisa Makanan, Konstribusi Zat Gizi dan Biaya Makan Pasien Rawat Inap di RSUD Salatiga. Skripsi.

Ilmu gizi: untuk mahasiswa dan profesi jilid 1 / Achmad Djaeni Sediaoetama. (n.d.). http://library.um.ac.id/free-contents/index.php/buku/detail/ilmu-gizi-untuk-mahasiswa-dan-profesi-jilid-1achmad-djaeni-sediaoetama-36277.html

Irawati, I., Prawiningdyah, Y., \& Budiningsari, R. D. (2010). Analisis sisa makanan dan biaya sisa makanan pasien skizofrenia rawat inap di Rumah Sakit Jiwa Madani Palu. In Jurnal Gizi Klinik Indonesia (Vol. 6, Issue 3, p. 123). https://doi.org/10.22146/ijcn.17720

Kemenkes RI. (2013). Pedoman-Pelayanan-Gizi-Rs-2013.Pdf. In Pedoman PGRS (pp. 1-165).

Mas'ud, H., Rochimiwati, S. N., \& Rowa, S. S. (2015). Studi evaluasi sisa makanan pasien dan biaya makanan pasien di rsk dr tadjuddin chalid dan rsud kota makassar. Media Gizi Pangan.

Nida, K., Efendi, R., \& Norhasanah. (2011). Faktor-faktor yang Berhubungan dengan Sisa Makanan Pasien Rawat Inap di Rumah Sakit Jiwa Sambang Lihum. Jurkessia.

Puruhita, N. et al. (2014). Gambaran Sisa Makanan dan Mutu Makanan yang Disediakan Instalasi Gizi RSUP DR. Kariadi Semarang. Jnh. 
Studi, P., Masyarakat, G., Sumberdaya, D. A. N., \& Pertanian, F. (2006). DAN STATUS GIZI PENDERITA SKIZOFRENIA DI RUMAH SAKIT Dr. H . MARZOEKI MAHDI BOGOR.

Tanuwijaya, L. K., Di, P., Adhyatma, R., Umihani, A., Puruhita, N. et al., Irawati, I., Prawiningdyah, Y., Budiningsari, R. D., Rijadi, C. B., \& Ellizabet, L. (2010). Hubungan Rasa Penampilan Makanan dan Faktor Lainnya Terhadap Daya Terima Makanan Lunak Pada Pasien Dewasa di Gedung Perawatan Umum RSPAD Gator Soebroto (Skripsi). Indonesian Journal of Human Nutrition, 2(1), 123. kalteng.litbang.pertanian.go.id

Wirasamadi, N. L. P., Adhi, K. T., \& Weta, I. W. (2015). Analisis Sisa Makanan Pasien Rawat Inap di RSUP Sanglah Denpasar Provinsi Bali. Public Health and Preventive Medicine Archive. https://doi.org/10.15562/phpma.v3i1.91 